\title{
Increased Sensitization to Mold Allergens Measured by Intradermal Skin Testing following Hurricanes
}

\author{
Diego Saporta ${ }^{1}$ and David Hurst ${ }^{2}$ \\ ${ }^{1}$ Private Practice, Associates in ENT \& Allergy, Elizabeth, NJ, USA \\ ${ }^{2}$ Tufts University, Boston, MA, USA \\ Correspondence should be addressed to Diego Saporta; dsaporta@gmail.com
}

Received 21 January 2017; Accepted 28 March 2017; Published 9 April 2017

Academic Editor: Evelyn O. Talbott

Copyright (c) 2017 Diego Saporta and David Hurst. This is an open access article distributed under the Creative Commons Attribution License, which permits unrestricted use, distribution, and reproduction in any medium, provided the original work is properly cited.

\begin{abstract}
Objective. To report on changes in sensitivity to mold allergens determined by changes in intradermal skin testing reactivity, after exposure to two severe hurricanes. Methods. A random, retrospective allergy charts review divided into 2 groups of 100 patients each: Group A, patients tested between 2003 and 2010 prior to hurricanes, and Group B, patients tested in 2014 and 2015 following hurricanes. Reactivity to eighteen molds was determined by intradermal skin testing. Test results, age, and respiratory symptoms were recorded. Chi-square test determined reactivity/sensitivity differences between groups. Results. Posthurricane patients had 34.6 times more positive results $(p<0.0001)$ at weaker dilutions, all tested molds were found to be more reactive, and $95 \%$ had at least one positive test versus only $62 \%$ before the hurricanes $(p<0.0001)$; average mold reactivity was $55 \%$ versus $16 \%$ while $17 \%$ of patients reacted to the entire panel versus none before the hurricanes $(p<0.0001)$. The posthurricane population was younger $(p<0.001)$ and included more patients with asthma or lower respiratory symptoms $(p<0.05)$. Conclusion. Reactivity and sensitization to mold allergens increased compared to patients before the hurricanes. This supports climatologists' hypothesis that environmental changes resulting from hurricanes can be a health risk as reflected in increased allergic sensitivities and symptoms and has significant implications for physicians treating patients from affected areas.
\end{abstract}

\section{Introduction}

Northern New Jersey was affected by two catastrophic storms: Hurricane Irene in 2011 and Hurricane Sandy in 2012. The storms covered an extensive area leading to widespread destruction [1] with severe damage including loss of life [2]. Following these storms wide areas of the state remained underwater for several days.

Hurricanes are climactic events of catastrophic proportion. It has been clearly established that people exposed to mold after floods like the ones resulting from hurricanes frequently develop allergy symptoms and asthma [3-5]. Flooding following a hurricane is a key factor for mold growth and may be an important risk for exposed individuals [3].

Significant changes in intradermal skin testing (IDT) results during routine patient evaluation for allergic conditions were first noted beginning in late 2011 and more clearly during 2012. These changes were apparent for all tested allergens. A pattern of increased sensitivity and reactivity to molds was observed as tests yielded many more positive skin reactions and, frequently, a weaker allergen concentration was required to elicit skin responses. The study was conducted to determine if the change in reactivity and sensitivity observed in the tested patients was real. While demonstrating this point is relatively simple as will be shown in this paper, explaining why this is happening is more difficult. Certainly hurricanes Irene and Sandy produced the conditions that, as specifically mentioned in the literature [6-8], encourage mold growth. Could this potential mold growth have, in any way, affected the health of the exposed population? The fact is that, at the time of this writing, we find more complex patients whose health appears to be more affected. The intention of this paper is just to report about the observed changes in skin reactivity and sensitivity. This study is the first to compare the results of mold allergy testing performed on a population of 
TABLE 1: Demographics.

\begin{tabular}{lcccc}
\hline & Male/female & Age (SD) & Age $\leq 18$ & \\
\hline A (2010) & $40 / 60$ & $44(17)$ & 12 & 25 \\
B (2015) & $36 / 64$ & $34(18)$ & 29 & 39 \\
$p$ value & N/S & $<0.001$ & $<0.01$ & $<0.05$ \\
\hline
\end{tabular}

Age (SD): average patient's age (standard deviation).

Age $\leq 18$ : number of patients, 18 years old or younger.

LRS: number of patients with asthma or lower respiratory symptoms.

A (2010): Group A, including tests performed in or before 2010 .

B (2015): Group B, including tests performed in 2014 and 2015.

N/S: not significant.

TABle 2: Number of positive skin tests per dilution.

\begin{tabular}{lccccccc}
\hline Dilution & $6(1: 15625)$ & $5(1: 3125)$ & $4(1: 625)$ & $3(1: 125)$ & $2(1: 25)$ & $1(1: 5)$ & Totals \\
\hline A (2010) & 0 & 2 & 6 & 27 & 216 & 34 & 285 \\
B (2015) & 5 & 11 & 228 & 125 & 481 & 137 \\
\hline
\end{tabular}

Numbers and percentages coincide as they are based on 100 cases.

Dilution 6 through 1 are 1:5 dilutions of the allergenic extract.

Totals: total number of positive mold tests in 100 tests (or 1800 individual mold tests).

A (2010): Group A, including tests performed in or before 2010.

B (2015): Group B, including tests performed in 2014 and 2015.

${ }^{* *} p<0.0001$.

a clearly defined geographical area before and after this area suffered the effects of two hurricanes.

\section{Methods}

Consecutive allergy charts were gathered and separated according to testing dates in two groups with one hundred cases each. Group A included those tested from 2003 to 2010, before the hurricanes, and Group B included those tested after the hurricanes in 2014 and 2015. Changes in skin reactivity had begun to be noted in late 2011 but appeared to be more evident each year following the hurricanes. To clarify the possible effect of this variable, we chose to eliminate all test results between the years 2011 to 2013 including only 2014 and 2015 for the posthurricane group, similar to the patient selection process used in our previous report on the effect of hurricanes on skin reactivity to dust and pollen [9]. Inclusion criteria were patients of any sex or age, with symptoms of allergic rhinitis with or without asthma, or lower respiratory symptoms (LRS) (i.e., symptoms pertaining to the lower airway but not formally diagnosed as asthma), provided that these patients were tested for the same panel of 18 molds.

The date of test, age, sex, presence of asthma or LRS, and test results were recorded. Any patients tested during both time periods were excluded to eliminate the potential effect of immunotherapy on skin reactivity of patients tested after a receiving immunotherapy. Test results were recorded as the diameter in millimeters $(\mathrm{mm})$ of each test wheal at each dilution. A statistician compared results of the preand posthurricane testing. The chi-square test was used to determine the differences in reactivity/sensitivity between groups. A probability $p<0.05$ was considered significant. Institutional Review Board (IRB) approval was obtained from Trinitas Medical Center, 225 Williamson Street, Elizabeth, NJ.
Intradermal Dilutional Skin Test (IDT) was performed on all patients according to guidelines from the American Academy of Otolaryngic Allergy (AAOA) [10, 11]. Briefly, successive serial 5-fold dilutions of each allergenic extract were prepared and conventionally labeled as Dilutions 1 to 6 . Dilution 1 was five times weaker than the allergenic extract (1:5), Dilution 2 was 1:25, Dilution 3 was 1:125, Dilution 4 was $1: 625$, Dilution 5 was $1: 3125$, and Dilution 6 was $1: 15,625$.

The test consists of injecting $0.01 \mathrm{~mL}$ of allergen to produce a $4 \mathrm{~mm}$ wheal and measuring its diameter $10-15$ minutes after injection. The first reactive wheal, called the End Point (EP), represents the minimal antigen concentration able to elicit a skin response $2 \mathrm{~mm}$ larger than the control which usually measures $5 \mathrm{~mm}$. Mold allergens were obtained from the manufacturer as weight/volume $(W / V)[12]$.

The mold panel consisted of the same 18 molds for both groups. The distribution of positive results in each dilution and the prevalence of individual tested molds were analyzed in Tables 1-6.

\section{Results}

Both groups had a similar distribution of males and females. Group B had more patients (18 or younger), $29 \%$ versus $12 \%$ in Group A $(p<0.01)$, and more patients with asthma or LRS, $39 \%$ versus $25 \%(p<0.05)$ (Table 1$)$. Group B had 3.5 times more total reactions (987 versus 285) $(p<0.0001)$ as well as more reactions to each of the dilutions tested. No positive test results occurred at Dilution 6 in Group A yet this occurred 5 times in Group B (Table 2).

Among both groups the majority of the positive reactions occurred for the dilutions with strong concentrations of allergen (Dilutions 1, 2, and 3): 743/987 (75\%) for Group B and 
TABLE 3: Low reactors versus high reactors.

\begin{tabular}{lccc}
\hline & Strong allergen concentration (Dil 1, 2, 3) & Weak allergen concentration (Dil 4, 5, 6) & Totals \\
\hline A (2010) & $277(97 \%)$ & $8(3 \%)$ & 285 \\
B (2015) & $743(75 \%)^{* *}$ & $244(25 \%)^{* *}$ & 987 \\
\hline
\end{tabular}

Dil 1, 2, 3: first to third dilutions from the extract $(1: 5 ; 1: 25 ; 1: 125)$. These have a stronger allergen concentration.

Dil 4, 5, 6: fourth to sixth dilution form the extract $(1: 625 ; 1: 3125 ; 1: 15625)$. These have a weaker allergen concentration.

Totals: total number of positive mold tests in 100 tests (or 1800 individual mold tests).

A (2010): Group A, including tests performed in or before 2010 .

B (2015): Group B, including tests performed in 2014 and 2015.

${ }^{* *} p<0.0001$.

TABLE 4: Number of positive results per panel.

\begin{tabular}{lcccc}
\hline & Reactive tests & None & 11 or more & \\
\hline A (2010) & $62 / 100$ & 38 & 4 & 0 \\
B (2015) & $95 / 100$ & 5 & 44 & 17 \\
$p$ value & $p<0.0001$ & $p<0.0001$ & $p<0.0001$ & $p<0.0001$ \\
\hline
\end{tabular}

Reactive tests: number of patients that had at least one positive individual mold test. It includes all the information in this table and patients that had between 1 and 10 positive results not shown in this table.

None: none of the 18 allergens reacted during the test.

11 or more: 11 or more of the allergens were found to be reactive during the test.

18 (all reactive): the 18 allergens reacted during the test (these are part of the "11 or more" column).

A (2010): Group A, including tests performed in or before 2010

B (2015): Group B, including tests performed in 2014 and 2015.

All results are also percentages (100 patients in each group).

277/285 (97\%) for Group A ( $p<0.0001$ ). Twenty-five percent (244/987) of the positive reactions in Group B occurred with weak allergen concentration (Dilutions 4,5 , and 6 ), versus $3 \%$ in Group A $(8 / 285)(p<0.0001)$ (Table 3). This suggests that the skin sensitivity to molds in the posthurricane group had significantly increased.

Before the hurricanes, $62 \%$ of the patients had at least one positive mold test. After the hurricanes this increased to $95 \%$ ( $p<0.0001)$. Before the hurricanes $38 \%$ of the patients were nonreactive to any mold compared to $5 \%$ of posthurricane patients $(p<0.0001)$. No patient reacted to all tested molds in Group A but $17 \%$ of the patients did so in Group B $(p<0.0001)$ and, among Group B, $44 \%$ of the patients reacted to 11 or more molds as compared to $4 \%$ in Group A $(p<0.0001)$ (Table 4$)$. On average, $55 \%$ of molds were reactive in Group B as compared to $16 \%$ among Group A $(p<0.0001)$ (Table 5). In the posthurricane test example there are more positive reactions and the EPs tended to occur at weaker dilutions. Observation of this disparity is what motivated this study. Unlike our previous report on changes in skin reactivity following dust, epidermals, and pollen tests [9], mold tests rarely produced unusually large wheals.

The molds whose reactivity was greater than 1 standard deviation above average $(15.83+6.6$ for Group A and 55.0 +8.0 for Group B) are marked in italic in Table 6. These included Epidermophyton, Trichophyton, and Rhizopus in Group A and the same three plus Penicillium in Group B.

\section{Discussion}

Hurricanes Irene and Sandy caused flooding that kept a wide geographical area underwater for several days $[13$, 14]. Buildings that remain wet for $48-72$ hours following major hurricanes and floods frequently develop visible and extensive mold growth [4]. Some reports have been published following Hurricane Katrina $[15,16]$, but they did not evaluate the same geographical population both before and after that hurricane. In our case both groups of patients belong to the same geographical area, and both groups were tested by the same practitioner, using the same intradermal testing technique.

There is a strong association between exposure to waterdamaged homes and development of upper and lower respiratory disease [3]. A worldwide increase in asthma and allergic rhinitis prevalence has been reported over the last two to three decades [17]. This increase appeared to be greater in children as asthma affects $20 \%-25 \%$ of the total population but $20 \%-40 \%$ of the childhood population [18]. Nasal allergy symptoms and asthma exacerbations are prominent manifestations of mold allergy [4]. Respiratory illness and asthma exacerbations have been noted following flooding [8] as a result of exposure to dampness or mold $[4,5,7,8]$, including reports of increased risk of respiratory arrest [8].

Our finding that posthurricane patients were reactive to many more allergens and at much weaker concentrations than in our preexposure group strongly suggests that the posthurricane population had become more sensitized and reactive to molds. The question that cannot be answered is as follows: Is this in any way related to exposure to a persistently damp environment? If so, similar changes might be expected to occur in other areas similarly affected by severe storms where flooding occurs.

The results showed an increased number of patients younger than 18 in Group B, as the percentage rose from $12 \%$ before the hurricanes to $29 \%$ after them (Table 1). Such change more likely reflects the results of their exposure and 
TABLE 5: Comparison of incidences of positive results for each individual mold allergen.

\begin{tabular}{lcc}
\hline Molds & A (2010) & B (2015) \\
\hline Alternaria & 11 & 56 \\
Aspergillus & 15 & 45 \\
Chaetomium & 14 & 46 \\
Cladosporium & 9 & 49 \\
Curvularia & 10 & 44 \\
Epicoccum & 13 & 50 \\
Fusarium & 13 & 52 \\
Smut & 8 & 58 \\
Helminthosporium & 20 & 55 \\
Mucor & 19 & 51 \\
Penicillium & 15 & 64 \\
Phoma & 16 & 56 \\
Pullularia & 8 & 52 \\
Rhizopus & 33 & 65 \\
Stemphylium & 15 & 52 \\
Candida & 16 & 50 \\
Trichophyton & 25 & 68 \\
Epidermophyton & 25 & 72 \\
\hline Totals & 285 & $987^{*}$ \\
\hline AVG (SD) & $15.83(6.6)$ & $55.00(8.0)$ \\
\hline
\end{tabular}

AVG (SD): average number of times a mold was reactive in each group (standard deviation).

A (2010): Group A, including tests performed in or before 2010.

B (2015): Group B, including tests performed in 2014 and 2015.

All results are also percentages (100 patients in each group), so each number represents how many times that mold was reactive in 100 tests. ${ }^{*} p<0.0001$.

not necessarily selection bias, which would be in agreement with findings reported in the literature [18].

Group B had a higher incidence of positive results to both strong and weak mold allergen concentrations (Table 3). Positive responses at weak allergenic concentration were an infrequent finding before the hurricanes, occurring in only $3 \%$ of the cases as compared to $25 \%$ of the cases in Group B, an 8 -fold increase. The difference in reactivity to allergy testing between the two groups in this study suggests that flooding after hurricanes may have been instrumental in sensitizing the exposed patient population to molds. Our finding that after the hurricanes $55 \%$ of patients reacted to molds versus $16 \%$ before and that the reactivity to each individual mold increased beyond that seen in Group A (Table 5) supports the hypothesis that the posthurricane population is more sensitized and reactive to molds which may be related to having been exposed to a persistently damp environment. This also supports the hypothesis that the posthurricane group represents a more sensitized and sicker population. Physicians working in other areas affected by flooding may find more patients with asthma or LRS, including a larger number of symptomatic children. Prevention strategies to minimize reactions during testing or treatment should be implemented. The limitations of a retrospective chart review are obvious in that all people from the same geographic
TABLE 6: Positive mold results arranged by incidence.

\begin{tabular}{lcccc}
\hline & \% pos & A (2010) & B (2015) & $\%$ pos \\
\hline$(1)$ & 33 & Rhizopus & Epidermophyton & 72 \\
$(2)$ & 25 & Epidermophyton & Trichophyton & 68 \\
$(3)$ & 25 & Trichophyton & Rhizopus & 65 \\
$(4)$ & 20 & Helminthosporium & Penicillium & 64 \\
$(5)$ & 19 & Mucor & Smut & 58 \\
$(6)$ & 16 & Candida & Alternaria & 56 \\
$(7)$ & 16 & Phoma & Phoma & 56 \\
$(8)$ & 15 & Aspergillus & Helminthosporium & 55 \\
$(9)$ & 15 & Penicillium & Fusarium & 52 \\
$(10)$ & 15 & Stemphylium & Pullularia & 52 \\
$(11)$ & 14 & Chaetomium & Stemphylium & 52 \\
$(12)$ & 13 & Epicoccum & Mucor & 51 \\
$(13)$ & 13 & Fusarium & Candida & 50 \\
$(14)$ & 11 & Alternaria & Epicoccum & 50 \\
$(15)$ & 10 & Curvularia & Cladosporium & 49 \\
$(16)$ & 9 & Cladosporium & Chaetomium & 46 \\
$(17)$ & 8 & Pullularia & Aspergillus & 45 \\
$(18)$ & 8 & Smut & Curvularia & 44 \\
\hline
\end{tabular}

$\%$ pos: number (and percentage) of times individual mold was reactive in each group.

A (2010): Group A, including tests performed in or before 2010. B (2015): Group B, including tests performed in 2014 and 2015. Italic: outliers (incidence higher than average + STD).

would have been exposed to the hurricane, thus making it impossible to establish a local control group. We therefore chose populations representing pre- and posthurricanes. A prospective study, though ideal, is probably impossible, as predicting where a hurricane might occur is most difficult.

Our finding that posthurricane patients were reactive to many more allergens and at much weaker concentrations than in our preexposure group strongly suggests that the posthurricane population had become more sensitized and reactive to molds.

\section{Conclusions}

The results of 100 intradermal tests for molds on patients presenting to an allergy practice, after two major hurricanes affected the New Jersey coast, appeared to be different from the same tests performed on an identical number of patients before the hurricanes. The posthurricane test results suggest that these patients have experienced an increased reactivity and sensitivity to mold.

Overall, posthurricane patients presented at a significantly younger age $(p<0.01)$, had asthma or LRS more frequently $(p<0.05)$ (Table 1$)$, and had a 3.5 times increase in the overall number of positive responses (987 versus 285) $(p<0.0001)$, including more positive reactions to weaker concentrations of allergen (Table 2). Sensitivity to 18 tested molds was markedly increased among posthurricane patients. Ninety-five percent in Group B versus 62\% in Group A reacted to at least one mold $(p<0.0001)$ (Table 4$)$. On average, $55 \%$ of molds were reactive in Group B as compared 
to only $16 \%$ among Group A $(p<0.0001)$ (Table 5). In Group $\mathrm{B}, 17 \%$ reacted to all tested molds, while no patient in the prehurricane group did so (Table 4).

It cannot be concluded that floods are directly responsible. Yet it is possible that floods following a major climatic event such as hurricanes may predispose patients to develop or worsen allergic rhinitis and/or lower respiratory airway disease. The increased mold sensitivity we report could be a confounding factor which might explain why more patients developed allergic rhinitis, asthma, or LRS following the hurricanes.

This study supports the hypothesis of climatologists that environmental changes resulting from hurricanes can be a significant health risk as suggested by the increased allergic sensitivities and symptoms among the exposed population which we document in this study.

These findings have significant implications for physicians who treat patients exposed to flooding disasters. Large scale studies are needed to confirm these observations.

\section{Disclosure}

This paper was presented at the 75th AAOA Annual Meeting in San Diego, CA.

\section{Conflicts of Interest}

The authors declare that there are no conflicts of interest related to this paper.

\section{Acknowledgments}

The statistical analyses were performed by Y. M. Samra, Ph.D. in Operations Management and Strategic Management, Manhattan College, New York, NY.

\section{References}

[1] https://en.wikipedia.org/wiki/Hurricane_Irene.

[2] https://en.wikipedia.org/wiki/Hurricane_Sandy.

[3] K. J. Cummings, J. Cox-Ganser, M. A. Riggs, N. Edwards, G. R. Hobbs, and K. Kreiss, "Health effects of exposure to waterdamaged New Orleans homes six months after Hurricanes Katrina and Rita," American Journal of Public Health, vol. 98, no. 5, pp. 869-875, 2008.

[4] M. Brandt, C. Brown, J. Burkhart et al., "Mold prevention strategies and possible health effects in the aftermath of hurricanes and major floods," MMWR. Recommendations and Reports, vol. 55, no. RR-8, pp. 1-27, 2006.

[5] Institute of Medicine, Damp Indoor Spaces and Health, The National Academies Press, Washington, DC, USA, 2004.

[6] J. J. K. Jaakkola, B.-F. Hwang, and N. Jaakkola, "Home dampness and molds, parental atopy, and asthma in childhood: a sixyear population-based cohort study," Environmental Health Perspectives, vol. 113, no. 3, pp. 357-361, 2005.

[7] Centers for Disease Control and Prevention (CDC), "Morbidity and mortality associated with Hurricane Floyd-North Carolina, September-October 1999," Morbidity and Mortality Weekly Report, vol. 49, no. 17, pp. 369-372, 2000.
[8] A. M. Pope, R. Patterson, and H. Burge, Eds., Indoor Allergens: Assessing and Controlling Adverse Health Effects, Committee on the Health Effects of Indoor Allergens, National Research Council, 1993, http://www.nap.edu/catalog/2056.html.

[9] D. Saporta, "Changes in skin allergy testing reactivity observed after a hurricane. is the environment responsible?" SOJ Immunology, vol. 3, no. 3, pp. 1-6, 2015.

[10] R. L. Mabry, Skin End Point Titration, AAOA Monograph Series, Thieme Medical Publishers, New York, NY, USA, 1994.

[11] J. A. Fornadley, "Skin testing in the diagnosis of inhalant allergy," in Allergy and Immunology, an Otolaryngic Approach, J. H. Krouse, S. J. Chadwick, B. R. Gordon, and M. J. Derebery, Eds., pp. 114-123, Lippincott Williams \& Wilkins, Philadelphia, $\mathrm{Pa}$, USA, 2002

[12] Alk-Abello Inc., 1700 Royston Lane, Round Rock, Tex, USA.

[13] http://www.huffingtonpost.com/news/hurricane-irene-2011/.

[14] http://www.huffingtonpost.com/news/hurricane-sandy-2012/.

[15] D. N. Barbeau, L. F. Grimsley, L. E. White, J. M. El-Dahr, and M. Lichtveld, "Mold exposure and health effects following hurricanes Katrina and Rita, Annual Review of Public Health, vol. 31, no. 1, pp. 165-178, 2010.

[16] L. F. Grimsley, J. Wildfire, M. Lichtveld et al., "Few Associations found between Mold and Other Allergen Concentrations in the Home versus Skin Sensitivity from Children with Asthma after Hurricane Katrina in the Head-Off Environmental Asthma in Louisiana Study," International Journal of Pediatrics, vol. 2012, Article ID 427358, 9 pages, 2012.

[17] B. Lundbäck, "Epidemiology of rhinitis and asthma," Clinical and Experimental Allergy, vol. 28, no. 2, pp. 3-10, 1998.

[18] World Allergy Organization (WAO), R. Pawankar, G. W. Canonica, S. T. Holgate, and R. F. Lockey, Eds., White Book on Allergy, World Allergy Organization, Milwaukee, Wis, USA, 2012. 


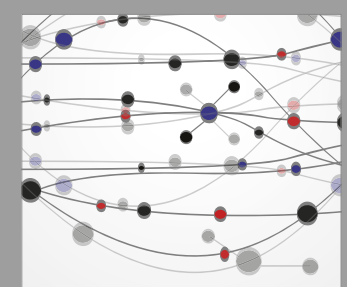

The Scientific World Journal
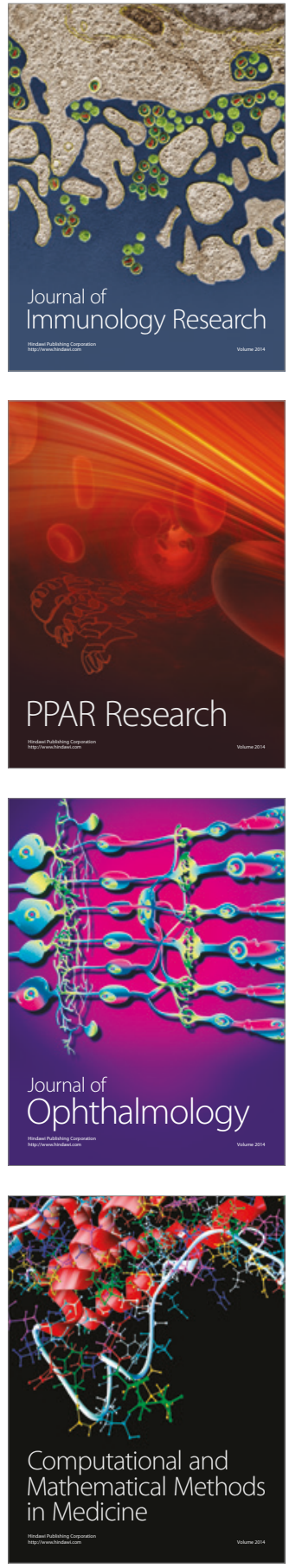

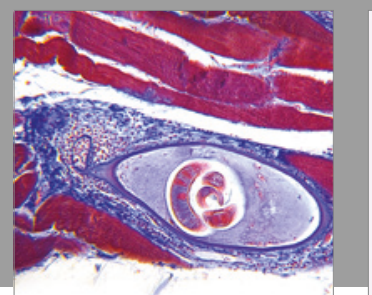

Gastroenterology Research and Practice
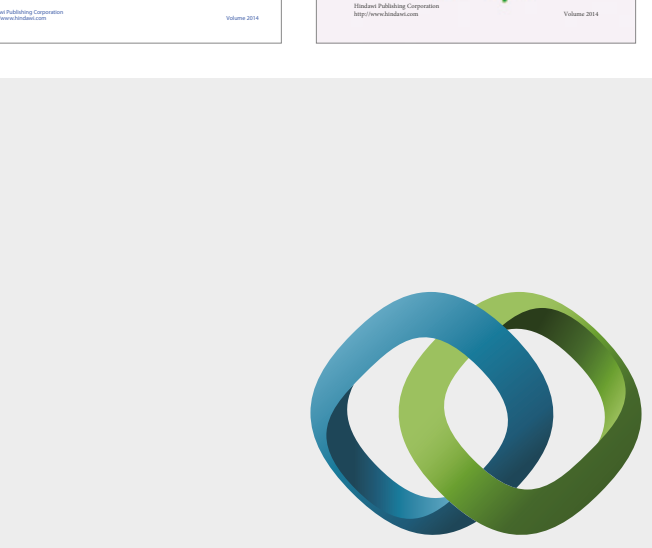

\section{Hindawi}

Submit your manuscripts at

https://www.hindawi.com
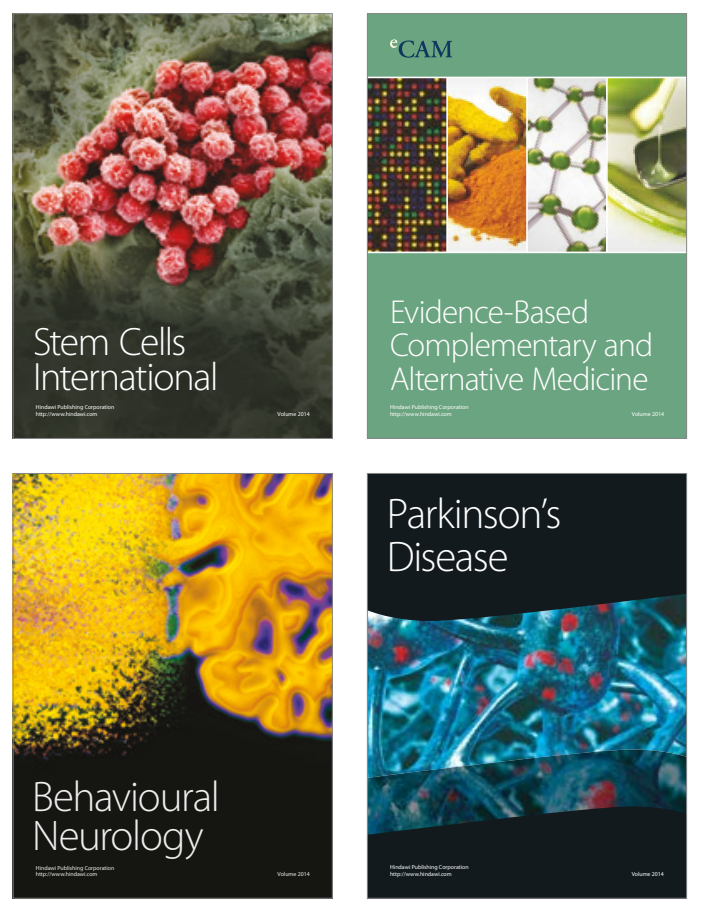
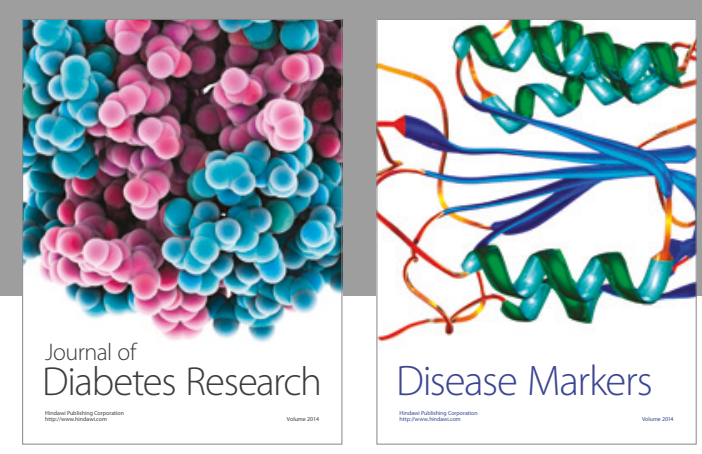

Disease Markers
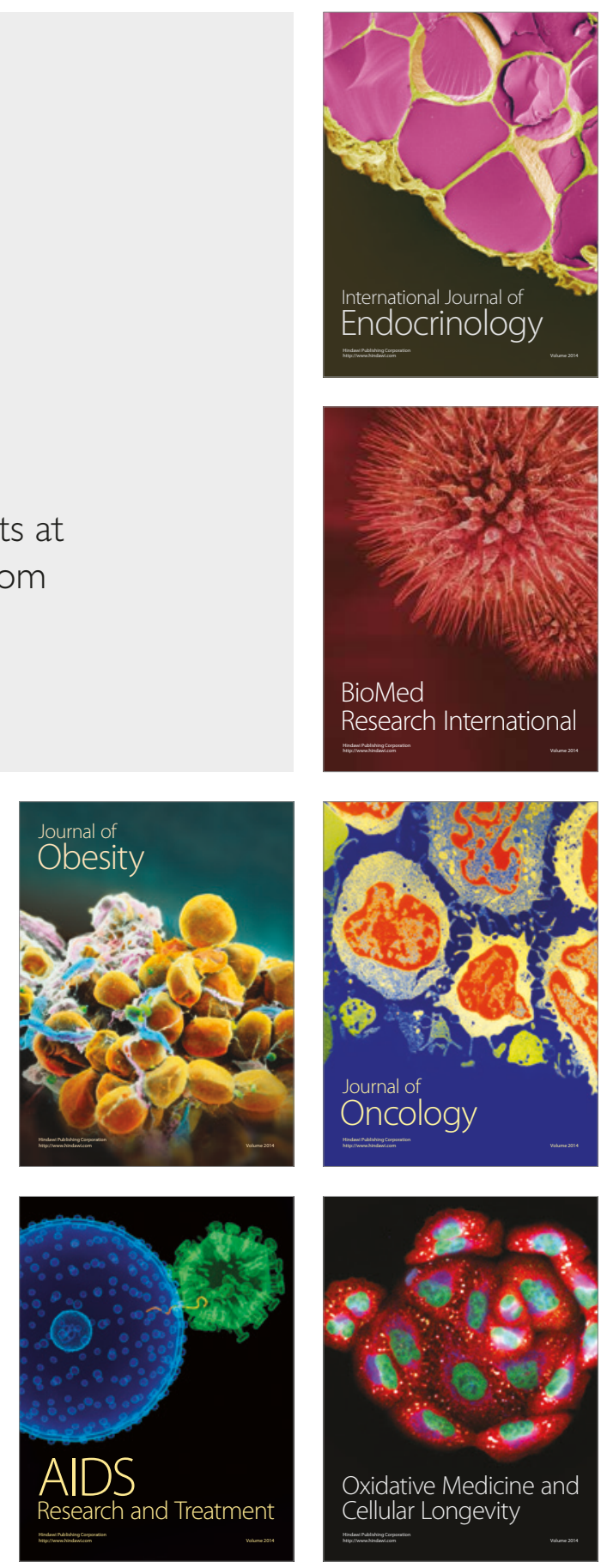